\title{
AN ECONOMIC ANALYSIS OF THREATS AND \\ THEIR ILLEGALITY: BLACKMAIL, EXTORTION, AND ROBBERY
}

\section{STEVEN SHAVELL $\dagger$}

The subject of this Article is the making of threats and the working of, and social need for, laws against them. I emphasize blackmail-by which I mean threats to expose information unless money (or something else of value) is surrendered-but I devote attention also to extortion (threats to cause injury to a person or to his property in the future) and to robbery (threats to do immediate physical harm to a person), as well as to certain commonly made threats that are not illegal (for example, threatening to withdraw business unless price is lowered). ${ }^{1}$

Section I of the Article is concerned with a purely descriptive, theoretical analysis of threats, assuming that parties act in a largely self-interested way and with due forethought. ${ }^{2}$ The point I initially consider is that to the degree that threats will yield gains, potential threateners will invest effort in obtaining information for purposes of blackmail and, more generally, in placing themselves in positions allowing them to make threats. Likewise, to the extent potential victims fear threats, they will endeavor to avoid becoming vulnerable to threats. This preparatory behavior of threateners and of victims will be affected by legal rules that punish threats. By reducing the anticipated return from threats, the rules discourage threateners from devoting effort to the making of threats and lead victims to do less to protect themselves from threats.

† Professor of Law and Economics, Harvard Law School. I wish to thank Louis Kaplow and A. Mitchell Polinsky for comments, Paul Taylor for research assistance, and the National Science Foundation for research support.

1 The term "blackmail" is sometimes interpreted more broadly than it is here, to encompass extortion. In fact, the early meaning of blackmail was limited to threats to do physical harm. For a recent discussion of blackmail and extortion, see James Lindgren, Unraveling the Paradox of Blackmail, 84 CoLUM. L. REv. 670, 673-76 (1984); for an extensive description of blackmail and extortion in English law, see Glanville L. Williams, Blackmail, 1954 CRIM. L. REV. 79; and for an examination of the evolution of the crimes of robbery, blackmail, and extortion in English law, see W.H.D. Winder, The Development of Blackmail, 5 MOD. L. REv. 21 (1941).

2 This feature of the analysis (along with its consequentialist normative aspect, to be described) is, of course, the hallmark of "economic" analysis of law and explains the use of the word in the title of the present Article. 
After examining behavior preparatory to threats, I investigate the actual making of threats, focusing on the very real question of how a threat can succeed. A person making a threat faces a double problem. On one hand, his threat must be credible. The intended victim must believe there to be a significant chance that the threat will be carried out if and only if he does not accede to it; otherwise, he may have insufficient reason to bow to the will of the threatener. On the other hand, the victim must believe that if he does reward the threatener, he, the victim, will gain thereby and not merely set himself up for further threats. These difficulties may render success in threat-making somewhat problematic, and I discuss partial solutions to them for threateners (for instance, I suggest that although the second difficulty involving repeated demands is often inevitable, a threatener may still be able to induce his victim to pay if the amount repeatedly demanded is appropriately small). Difficulties in making threats combined with possibilities of miscalculation lead to the risk that demands will be rejected and threats actually executed.

In Section II of the Article, I inquire about the social undesirability of threats and the social advantages of laws punishing them. In so doing, I employ a consequentialist notion of social welfare and evaluate threats with reference to their three types of effect: (1) those concerning threateners' and victims' preparatory behavior; (2) the anxiety and worry suffered by victims (whether or not threats ultimately are carried out); and (3) results flowing from the carrying out of threats or the satisfaction of demands. In examining the utility of legal rules for discouraging undesirable threats, I consider, among other things, the virtues of punishing preparatory behavior versus punishing the making of threats versus punishing the execution of threats.

In both sections, I apply the analysis to the three major types of threats. ${ }^{3}$ Regarding blackmail, I am naturally led to consider issues surrounding the social versus the private harm (or good) done by disclosure of information, and also issues involving the reporting of crime and law enforcement. The latter arise when the information a blackmailer threatens to reveal pertains to commission of a crime, for then blackmail itself might be thought to serve as a supplementary form of punishment. ${ }^{4}$

\footnotetext{
3 See supra note 1 and accompanying text.

${ }^{4}$ I argue, however, that rewards for reporting crime are superior to blackmail as a device for enhancing law enforcement, so that blackmail should be illegal even when
} 
In Section III of the Article, I offer concluding remarks. I should also say at the outset that I do not achieve any striking novelty here; I depend in many respects on the recent thoughtful analyses of blackmail by Landes and Posner, Ginsburg and Shechtman, and Lindgren. ${ }^{5}$

\section{DESCRIPTIVE ANALYSIS OF THREATS}

\section{A. Behavior Preparatory to the Making of Threats}

A person must often engage in certain preparatory activity to place himself in a position allowing him to make a threat. To carry out blackmail, a person must obtain information about the intended victim that the latter does not want revealed. To commit robbery, a person must find a potential victim in circumstances where he could not defend himself or secure help. Of course, it could be that a person fortuitously finds himself in a position allowing him to make a threat, as where a person chances upon information embarrassing to another. But individuals frequently undertake purposeful activity to gain advantages permitting them to make threats.

Similarly, potential victims of threats will want to reduce their vulnerability to threateners; they can do this in two ways. First, they can diminish the scale of the activities that expose them to risk. A person worried about the risk of blackmail from his infidelity can lower the number of unfaithful acts in which he engages; a person worried about the risk of blackmail from commission of a crime can reduce the number of crimes he commits; or a person worried

the blackmail information concerns criminality. See infra text accompanying notes 37 38.

5 See Douglas H. Ginsburg \& Paul Shechtman, Blackmail: An Economic Analysis of the Law, 141 U. PA. L. REv. 1849 passim (1993); William M. Landes \& Richard A. Posner, The Private Enforcement of Law, 4 J. LEGal STUD. 1, 42-44 (1975); Lindgren, supra note 1, passim. I am also informed by the following articles examining blackmail from an economic perspective: Ronald H. Coase, The 1987 McCorkle Lecture: Blackmail, 74 VA. L. REV. 655 (1988); Daniel Ellsberg, The Theory and Practice of Blackmail, in BARGAINING: FORMAL THEORIES OF NEGOTIATION 343 (Oran R. Young ed., 1959); Richard A. Epstein, Blackmail, Inc., 50 U. CHI. L. REv. 553 (1983); Richard A. Posner, Blackmail, Privacy, and Freedom of Contract, 141 U. PA. L. REV. 1817 (1993). The present Article appears to add to the existing economically oriented literature chiefly in its descriptive analysis of threat-making. It also differs, though, in various ways in its normative analysis (see especially the discussion of whether blackmail is socially undesirable when the information that might be disclosed concerns a crime) and is more general in that it considers different types of threats. 
about robbery can reduce the number of times he is out and about at night. Second, a person can take precautions to lower the likelihood of threats given the scale of his activity. For instance, a person who has arranged a meeting with a lover in a hotel room can exercise the precaution of checking for hidden cameras and can double-lock the door.

The general influence of legal rules on the preparatory behavior of threateners and of victims is apparent. Rules that penalize the making of threats or their execution lower the expected return from this activity, ${ }^{6}$ and thus should lower the preparatory effort expended by potential threateners setting up threats. Threateners' preparatory efforts will also fall if such effort is itself punished (for instance, if drilling peepholes to be employed subsequently to obtain information for blackmail is penalized). A reduction in threateners' preparatory efforts will in turn lead potential victims not to fear threats as much, and will therefore increase the scale of the activities that expose them to risk and reduce their precautions.

\section{B. The Making of Threats: A Basic Model}

Let us now assume that a threatener is in a position to make a threat and discuss a simple model in which threats are made only once. ${ }^{7}$ Here, the central issue will be the credibility of the threat, by which is meant the victim's belief that the threat will be carried out if and only if he does not satisfy the demand made of him. Consider Figure I on the following page.

As illustrated, threatener $T$ makes a demand of victim $V$, which $V$ either accepts or rejects, and then $T$ either carries out his threat or does not. Assume as well that if $T$ carries out his threat, he will bear a cost or enjoy a benefit and that $V$ will suffer a harm.

What constitutes rational behavior for the parties in this situation? $V$ should often reject $T$ 's demand because his threat will not be credible. Specifically, suppose that it is costly for $T$ to carry out his threat. Then $T$ will do nothing whether or not $V$ accepts his demand, so $V$ should reject it. Similarly, suppose that it will give $T$ pleasure to carry out his threat. Then $T$ will carry out his threat whether or not $V$ accepts his demand, so again $V$ should reject it; he would gain nothing by accepting the demand.

6 See infra part I.B.

${ }^{7}$ For discussion of repeated threats, see infra part I.C. 


\section{FIGURE I}

Making Threats: The Single Demand Model

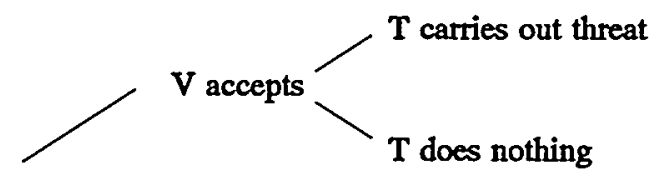

T makes demand

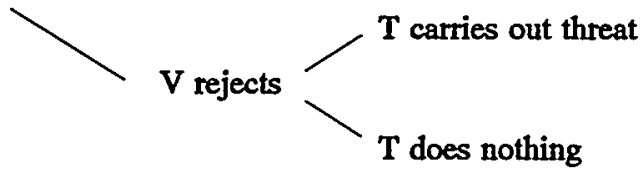

Plainly, for it to be rational for $V$ to accept $T$ s demand, it must be that $T$ 's threat will be carried out if, but only if, $V$ rejects the demand; for then $V$ will profit by meeting the demand. When will $T$ 's threat be carried out if and only if his demand is rejected? Several answers suggest themselves. ${ }^{8}$

One possibility is that $T$ will bear zero cost in carrying out his threat (as might nearly be true if the threat is to shoot a robbery victim or to reveal information about a blackmail victim). In this case, $T$ will be happy to carry out his threat if his demand is rejected, and also happy not to carry it out if his demand is accepted. In other words, a statement that $T$ would carry out his threat if and only if his demand is rejected is credible (even though barely so).

A second possibility is that $T$ has the psychological makeup whereby he would become angry about rejection of his demand. If so, $T$ would want to carry out his threat if his demand is rejected, but may not want to do so if it is accepted, perhaps because he

${ }^{8}$ See generally Thomas C. Schelling, The StRategy of Conflict 21-52, 81-203 (1960) (discussing how parties may make their threats credible and specifically mentioning among other elements the third and fourth possibilities noted below); Ellsberg, supra note 5, at 343-63 (amplifying Schelling's points in the context of blackmail). 
would then feel grateful or because there is a cost to carrying out the threat. ${ }^{9}$

A third possibility is of an entirely different nature: that $T$ will make a contract to have the threat carried out by a third party if and only if his demand is rejected. Such a contract, if legally or otherwise enforceable, may make $T$ 's threat credible. ${ }^{10}$

A fourth and closely related possibility is that $T$ has an interest in establishing and maintaining a reputation of carrying out threats if and only if his demands are rejected-because $T$ is in the business of making threats. ${ }^{11}$

Suppose, then, that for any of these reasons, $T$ will carry out his threat if and only if his demand is rejected. When would his demand be accepted? The answer, in the model of Figure I, is that it would be accepted as long as its amount did not exceed the harm that $V$ would suffer were the threat carried out. If $T$ has accurate knowledge of the harm that $V$ would suffer, he will demand exactly this amount, extracting the maximum from $V .^{12}$

Imperfect information, however, can lead to rejection of demands and execution of threats. If $T$ overestimates the harm to $V, T$ may demand more than $V$ would be willing to pay; $V$ will thus rationally reject the demand, and $T$ will then carry out his threat. ${ }^{13}$ Another way that imperfect information may lead to inefficient

${ }^{9}$ A numerical example may be useful here. Suppose that if his demand were rejected, $T$ would obtain a benefit of 10 from carrying out the threat, whereas if his demand is accepted he would bear a cost of 5 from carrying out the threat; in either case, if he does nothing, his gain is 0 . If $T$ 's demand is rejected, he will clearly carry out his threat, for a gain of 10 exceeds 0 ; but if his demand is accepted, he will not carry out his threat because he would rather gain 0 than lose 5 .

${ }^{10}$ I say "may" because there are a variety of difficulties that may arise with such contracts (apart from ensuring their enforceability). Suppose, for example, that $T$ would derive pleasure from revealing information about $V$. Even if he made a contract with a third party for that party to reveal information if and only if his demand were not met, if his demand were met, $T$ himself would still have an interest in revealing the information. Hence, accepting $T$ 's demand would do $V$ no good.

${ }^{11}$ Equivalently, $T$ may sell his ability to make a threat (as by selling embarrassing information) to such a business.

12 Suppose that the harm $V$ would suffer if the threat is carried out is 100 and that $T$ 's threat is credible. If $T$ knows that 100 is the harm $V$ would suffer, $T$ will know that any demand he makes up to 100 will be accepted by $V$, so $T$ will ask for 100 (or just under 100), and $V$ will be willing to pay that amount.

${ }^{13}$ If $T$ thinks the harm that $V$ would suffer is very likely to be 100 and very unlikely to be 50, $T$ will rationally demand 100: for usually this amount will be accepted, and when it is not, all that happens-assuming the situation in note 9 , supra-is that $T$ gets angry and carries out his threat, gaining 10 instead of 100 . The alternative of obtaining $\mathbf{5 0}$ for sure is not as good. Thus, when the harm $V$ would suffer is indeed 50, $V$ will reject $T$ 's demand of 100 , and $T$ will carry out his threat. 
decisionmaking is that $V$ may mistakenly think that $T$ will not carry out his threat and thus reject it, only to see the threat carried out. ${ }^{14}$

Finally, consider the question whether $T$ will want to make a demand in the first place (assuming that he is in the position to do so). The answer depends on the return he can expect from a demand, and the cost of making it and of possibly carrying out a threat. In the simplest case, where he and $V$ have perfect information and $T$ s demand is credible, $T$ will obtain a gross return equal to the harm to $V$, so he will make a threat if the expected costs of so doing are less than this amount. If $T$ 's information is imperfect, he will compare his expected return to his expected costs.

How do legal rules affect the behavior of parties, given that a threatener is in a position to make a threat? Rules that penalize the making of threats and their execution will generally increase the expected cost of making threats, and thus reduce the number of occasions in which a threatener will decide to make a threat. The threshold of gross return from a threat will have to be higher before a person who is in a position to make a threat will decide to do so. Furthermore, such rules may limit the circumstances in which threats are credible and reduce the probability that a threatener will make a threat.

To amplify this discussion, consider how the probability of detection and conviction for a threatener is determined. First, by making a threat, he suffers a risk of capture, as someone, especially the victim, may obtain proof of his behavior. Second, the victim's acceptance of a threatener's demand provides an additional opportunity for proof of his behavior to be obtained. ${ }^{15}$ Third, the carrying out of a threat may affect the probability of detection. In some contexts, executing a threat will increase the chances of detection, for it may furnish an additional opportunity for proof of a threat to be obtained. Also, the carrying out of a threat may

${ }^{14}$ In the example given in note 9 , supra, suppose that, contrary to fact, $V$ thinks it very likely that $T$ will bear a cost of 5 in carrying out his threat whether or not $V$ rejects the demand. $V$ will not believe that $T$ will carry out the threat if he rejects the demand, so that $V$ will reject $T^{\circ}$ s demand, and $T$ will carry out his threat.

15 A complication with regard to a discovery that $T$ is accepting payments is that this in itself may well not be illegal. If it is not illegal, then T's acceptance of payments must be combined with other evidence for it to help in convicting $T$ of making threats. Similarly, $T$ 's execution of a threat may not be illegal (suppose the threat is to expose information) and thus must be combined with other evidence to assist in convicting $T$. For further discussion on this point, see infra part II.B. 
increase the incentive of the victim or someone else to report the threat, as where a blackmail victim, having been exposed, no longer has anything to fear from reporting, or where a robbery victim becomes angry and wants revenge. It is possible, however, that the carrying out of a threat will reduce the probability of detection (for instance, if the threat is to kill the victim, thereby eliminating a source of information about the threat). If, though, the carrying out of a threat would increase the exposure of the threatener to detection, then the likelihood that his threat would be credible would be reduced by the presence of the legal rules under consideration.

Of course, the magnitude of the effect of legal rules depends importantly on the probability of detection and conviction, and this in turn depends on the likelihood of observation by third parties or the report of threats by victims.

\section{The Making of Threats: Model with Repeated Demands}

Let us now examine an extension of the basic model allowing for the possibility of repeated demands and repeated threats. In this version of the model, the new issue that arises is that if the victim accepts an initial demand, that may well not result in his being free from further demands. Consider Figure II on the following page.

The assumption is that after $V$ accepts or rejects, $T$ has the option of making another demand in addition to the option of carrying out his threat or doing nothing. It is also assumed that the situation portrayed repeats itself, that after $V$ accepts or rejects a possible second demand, there may be a third demand, and so on. ${ }^{16}$

16 The diagram reflects the implicit assumption that $T$ will not resume bargaining if he ever carries out his threat or does nothing. This assumption is made for simplicity but has justification in certain situations. For instance, in blackmail, if $T$ carries out his threat and exposes information, he no longer can carry out a threat. 
FIGURE II

Making Threats: The Multiple Demand Model

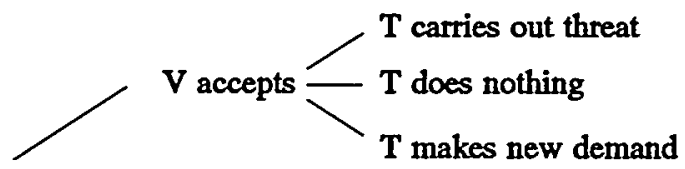

$\mathrm{T}$ makes demand
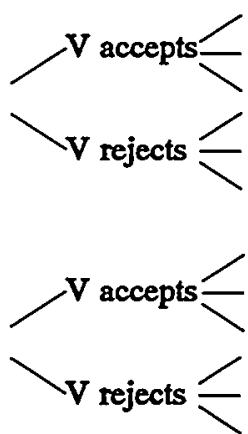

To understand the new issue, assume that $T^{\circ}$ s threat is crediblethat he will carry out his threat at any stage if and only if his demand is rejected (for concreteness, one might assume that $T$ would become angry if his demand were rejected). Now consider $T$ 's decision if $V$ accepts his initial demand. $T$ will be best off making a new demand if there is any probability that it will be accepted. ${ }^{17}$ Moreover, this logic applies at every stage. Hence, both $T$ and $V$ will realize that $T$ will be making repeated demands. What does this imply? It implies that what $V$ purchases when he makes a payment to $T$ is freedom from the threat for one period, until $T$ makes the next threat. Hence, for $V$ to be willing to pay $T$, $T$ 's demand each period must be "small," equal only to the value of freedom from the threat during the periods between demands. A succession of payments of this size is, however, quite rational for $V$

${ }^{17}$ If $T$ makes a new threat, he will obtain a positive expected return. If he does nothing more, he obtains zero. If he carries out his threat, he gains nothing or bears a cost. Hence, $T$ would make a new demand. 
to make. ${ }^{18}$ Further, notice that there is a self-reinforcing aspect of the situation under discussion: both $V$ and $T$ know that if $T$ were ever to carry out his threat, he would as a consequence lose all future payments-he would be killing the goose that lays the golden eggs. This should make $T$ want to continue to refrain from carrying out his threat as long as he is paid, giving $V$ greater confidence that $T$ will do so as long as $V$ continues payments.

Several observations are worth making about these conclusions. First, the outcome in which $V$ makes repeated payments to $T$ may be inferior in the eyes of both $V$ and $T$ to an outcome in which a single payment is made (with a present value equal to that of the stream of repeated payments). A single payment may be preferred by both parties because it would reduce bargaining and transaction costs; it might be preferred by $V$ because it would mean an early end to worry and anxiety, and by $T$ for liquidity reasons. If the parties want to arrange a single payment, they must somehow avoid their joint problem that $T$ will have an incentive to make repeated demands. One way in which a single payment could be arranged is, in principle, for $T$ to give $V$ the power to threaten him when the first payment is made. Notably, as I will discuss subsequently in the context of blackmail, $T$ could give $V$ information that $T$ would not want revealed; thus, after the first payment, $V$ and $T$ would each be able to threaten each other, and hence, after a single payment, there might be no more demands. Another way in which the problem might be solved is that $T$ may be in the business of making threats and thus, as discussed above, want to maintain a reputation that will inure to his long run benefit. If so, $T$ would have a reason to drop the matter after $V$ made a single payment. ${ }^{19}$

${ }^{18}$ A complete example may be helpful. Suppose that, as in note 9, supra, if T's demand is ever rejected, he would become angry and obtain a benefit of 10 from carrying out his threat, but whenever his threat is accepted, he would sustain a cost of 5 were he to carry out his threat. Suppose as well that if $T$ ever carries out his threat, $V$ will suffer a loss of 20 for each and every period thereafter. In this situation, it is reasonable for $T$ to demand 20 (or just under this amount) and to have the strategy of carrying out his threat if and only if any demand is rejected. Also, it is reasonable for $V$ to pay 20 every period. In the terminology of game theory, this constitutes a perfect equilibrium. Specifically, if $T$ has the stated strategy, it is obviously rational for $V$ to accept $T$ 's demand each period. T's strategy is also rational for him to pursue at each stage, for if he ever carries out the threat or drops the matter, the game is over and he obtains less than 20, whereas if he makes another demand he will obtain 20 . While this is only an example, I conjecture that it illustrates the nature of a solution to the repeated threat model under wide conditions. (This model, it seems, deserves to be studied formally.)

${ }^{19}$ Similarly, $T$ could conceivably contract with a third party to make only a single 
This is not to say, however, that $V$ and $T$ will necessarily want to arrange a single payment. $T$ may prefer a stream of payments because only in this way can he extract a share of $V$ 's future earnings. If $V$ receives income over time from employment or a business (and cannot borrow against future earnings), then the only way $T$ can obtain a significant share of $V$ s income is to take it in a series of payments. For this reason, if the harm that $T$ could impose on $V$ by carrying out his threat is sufficiently large, $T$ may prefer to collect a stream of payments.

A second observation is that the possibility that imperfect information will lead to rejection of demands and the carrying out of threats appears to be greater in the repeated context. There are more opportunities for demands to go wrong, to exceed what $V$ is willing to pay. Further, over time, the value $V$ places on freedom from execution of the threat may change, as may his willingness to make payments. If $T$ fails to gauge properly $V$ s situation, he may ask for too much and be rejected, and that may in turn prompt performance of the threat.

Third, the influence of legal rules is altered somewhat in the repeated context. The repetition of payments means that there are more chances for $T$ to be caught, and thus suggests that the power of the legal rules to deter is greater than would otherwise have been appreciated.

\section{Application to Different Types of Threat}

\section{Robbery}

How do robbers make their threats credible? First, if a robber carries a weapon that he appears to know how to employ, not only does he have a threat that is large in magnitude, but also one which may be easy for him to execute (to pull a trigger is virtually effortless) and one which, if carried out, may not increase (and could reduce) his likelihood of being caught. Hence, we may sometimes envision the situation as one in which the cost of carrying out a threat is small, making credibility of the threat easier to establish. Second, the possibility that a robber may enjoy carrying out his threat if he is thwarted may also be relevant. The personality type given to this reaction is probably correlated with certain characteristics of robbers (lack of education, anomie), and 
self-selection may also be at work-individuals with the personality type may choose to become robbers. In any case, we would expect to see attempts by robbers to convince victims that they would not mind, or would enjoy, carrying out threats if their demands are not met. Thus, robbers often display behavior patterns that lead victims to believe they are confronting sociopathic individuals who will carry out their threats. Robbers may commit minor acts (shove someone, push a knife to a person's throat) to help persuade victims that they are dealing with individuals who are willing to carry out threats. Despite the various efforts of robbers to make their threats credible, they obviously do not always succeed, and for this reason as well as others, robbers often commit violence.

It should be remarked that the issue of repeated threats is moot with regard to robbery. In a robbery situation, repeated threats are not possible, as once a person turns over his possessions to the robber, that is the end of the matter.

Legal rules against robbery undoubtedly reduce the amount of robbery substantially, despite the incidence of this crime. If there were no laws against robbery, the levels of precaution taken by potential victims and the curtailment of their activities arguably would be extraordinary, as would the efforts by robbers to commit robbery.

\section{Extortion}

An extortionist's problem of making his threat credible is in some respects more difficult than a robber's, because the extortionist's threat is not immediate and apparent and because his victim will have time to defend himself. While extortionists probably attempt to solve their credibility problems by the general techniques used by robbers, it also seems that they resort more often than do robbers to groups (neighborhood gangs, organized crime) with longterm stakes in maintaining a reputation for carrying out threats.

The threat of the extortionist often can be repeated, unlike that of the robber, for the nature of the extortionist's threat usually lends itself to repetition. If the threat is to burn down a store, for instance, this can ordinarily be repeated. We would therefore expect on the general grounds advanced above that extortion demands would be repeated. Moreover, an extortionist frequently would not want to arrange a single payment because the extortion victim often earns money over time and thus will yield more if the extortionist collects repeatedly. Thus, it is not surprising that 
extortion demands are in fact usually repeated (at least this is my impression).

There is little to add about the effect of legal rules to what has already been said. ${ }^{20}$ To the extent that extortion threats are anticipated, it would seem that there is an enhanced opportunity to catch an extortionist, other things being equal. Moreover, since organizations often are involved in extortion and organizations are easier to detect than single parties, extortion may be easier to detect than what might otherwise be supposed. The implication is not, of course, that we would expect to see extortion stamped out, and we do not. Rather, it is that the legal rules against extortion are probably effective in deterring a tremendous amount of that activity; in the absence of the enforcement of legal rules against extortion, we would likely be overrun by extortionate enterprise. ${ }^{21}$

\section{Blackmail}

It appears that a blackmailer should often face less difficulty in making his threat credible than a robber or extortionist because the cost of executing a blackmail threat is likely to be small by comparison. The direct cost to a blackmailer of actually carrying out his threat is ordinarily trivial; it takes almost no effort to mail a photograph or a document to someone. The cost to a blackmailer of carrying out his threat probably inheres mainly in any resulting increase in the risk of his being caught and punished. But the blackmailer can usually reveal his information anonymously, using the mail or the telephone. And even if he is caught revealing information, this is not a crime (unlike the extortionist's or the robber's threats), so it might be difficult to successfully prosecute the blackmailer in the absence of independent evidence that he had made a threat. All this suggests that the blackmail threat is frequently not very hard to make credible. Accordingly, blackmailers should not usually need to rely on a group's reputation to

${ }^{20}$ See supra parts I.A-C.

${ }^{21}$ In areas where the legal system is ineffective or has broken down, such as in regions of Bolivia and Colombia today, extortion is well known to engender serious avoidance efforts on the part of potential victims, extending even to the creation of private protective armies to act against extortionists. At the same time, the efforts of extortionists to set up opportunities for their activities are extensive. This is a chief occupation of certain guerrilla and bandit groups. See James Brooke, Kidnapping and "Taxes" Transform Guerrilla Inc., N.Y. TIMES, July 24, 1992, at D1. 
enhance the credibility of their threats, and it appears that blackmail is usually an individual activity. ${ }^{22}$

The threat of blackmail is one which can be repeated. A blackmailer virtually always retains the ability to reveal information. Even if he wants to extinguish his ability to reveal information, there is usually no way to convince a blackmail victim that the blackmailer does not have copies of photographs or other proof of the information the victim does not want revealed. ${ }^{23}$ This means that the victim should expect repeated demands and that a small stream of repeated payments will be made. This may also sometimes be seen as a problem by a blackmailer and his victim. Although I have no direct evidence that it is so regarded, one sees occasional reference to the issue in accounts of blackmail, ${ }^{24}$ and one certainly sees reference to the point that demands are seldom made only once. ${ }^{25}$

With regard to the effect of legal rules on blackmail, it is frequently difficult to obtain evidence that a blackmailer made a threat. Blackmail threats are occasions in which information is communicated, perhaps only verbally, and can ordinarily be concealed or designed so that the blackmailer's identity cannot be established. Moreover, the blackmailer can sometimes phrase the threats in a nuanced way to avoid crossing the line of criminality, even though the meaning of the threats will be clear to victims. Further, the victim of a blackmail threat may well have an incentive to hide the threat from the authorities, for reporting it may result

22 See, e.g., MIKE HePWORTH, BLACKMAIL: PUBLICITY AND SECRECY IN EVERYDAY LIFE 46-60 (1975) (describing traits and accounts of blackmail by master blackmailers).

${ }^{23}$ There are exceptions to this statement. Suppose that $I$ am blackmailing murderer $\mathrm{V}$ with the threat that I will turn over to the authorities the murder weapon, a gun, that $I$ have in my possession. If I instead surrender the gun to $V, I$ will end my ability to make further demands. But such instances appear to be rare.

${ }^{24}$ Consider, for example, the following conversation about blackmail in a detective novel by Lawrence Block:

"You pay it once and it's over."

"Back on Square A. How do I know that?"

"Because when you pay over the money, I give you a handle on me. I did something a few years ago. I could go to jail for it for a long time. I can write out a confession giving all the details. I'll give it to you when you pay the fifty thou .... That locks me in, keeps me from doing a thing."

Finally she said, "It might work."

LAWRENCE Block, Time to MURder and Create 45-46 (Jove Books 1983) (1977).

${ }^{25}$ See HEPWORTH, supra note 22, at 42 (discussing recurring demands for money as both a feature of blackmail and frequent cause of the blackmailer's undoing). 
in disclosure of the information he wants to keep secret. Unlike the victim of an extortion or robbery threat, the blackmail victim may suffer more if the threatener is brought to justice than if he is not. It is true that there is scope for the state to protect the blackmail victim from exposure of the information, but this will often be impossible. ${ }^{26}$. In addition, as explained above, the chances of convicting a blackmailer who carries out his threat are not high. Hence, one suspects that the ability of legal rules to prevent blackmail is often circumscribed.

At the same time, this limitation does not mean that the rules are of negligible effect. In their absence, it is probable that the scope of blackmail would be vastly increased due to growth of businesses specializing in this activity. ${ }^{27}$ All manner of activity aimed at gathering information for purposes of blackmail would occur, as would efforts to entice people into embarrassing situations. Furthermore, potential victims would take protective measures that they do not take today because of the remoteness of the chance of blackmail.

An additional issue concerning the effect of rules against blackmail involves situations where a blackmailer's information pertains to the commission of a crime. In such cases, does blackmail increase deterrence of crime, that is, the probability and magnitude of punishment for crime?

The illegality of blackmail would seem to reduce the probability that crime is punished, where by "punished" I mean either that the criminal is punished by the state or by having to pay a blackmailer. Because people will generally have less incentive to obtain information about the commission of crimes when blackmail is illegal, criminals who would have been discovered and then blackmailed may not be if blackmail is illegal. For instance, a neighbor of $X$ who has a suspicion that $X$ committed a crime and would blackmail him were this legal may not bother to investigate (say by looking for stolen goods) due to the illegality of blackmail. It is true that the illegality of blackmail will tend to increase the reporting of crime to

${ }^{26}$ For instance, the time the victim spends in court may be hard to conceal from co-workers or from a spouse, and may lead to discovery of the information that he wants to hide. Additionally, if the information is that the person committed a crime, he will be reluctant to go to the authorities, unless they had granted him immunity from prosecution (even in this case, he might be reluctant to go forward).

27 See Epstein, supra note 5, at 562 ("[T]here would then be an open and public market for a new set of social institutions to exploit the gains from [legalized blackmail]."). 
the authorities when people already have information about the commission of a crime; ${ }^{28}$ if $X$ 's neighbor already knows that $X$ committed a crime, the neighbor might report this if blackmail is illegal but may have kept quiet and committed blackmail if the law permitted otherwise. Such an event, however, amounts to a shift in the medium of punishment, not in the probability of punishment.

It appears, though, that the illegality of blackmail will often tend to increase the magnitude of punishment. As just mentioned, the illegality of blackmail should result in people who have information reporting it to the state more frequently than otherwise, and under plausible assumptions the state's punishment will be more severe than a blackmailer's. In particular, suppose that the criminal sanction includes imprisonment and that the assets of the victim are not very large. Then the maximum amount of money a blackmailer could extract would create less disutility for the criminal than the criminal sanction. For example, an embezzler with $\$ 5000$ in assets could pay a blackmailer at most $\$ 5000$, but spending fifteen years in jail would be a considerably more serious punishment. Moreover, part of the criminal sanction is public humiliation, a situation which is avoided in a blackmail arrangement. Hence, the suspicion is that with regard to many serious crimes, there would be a systematic reduction in the magnitude of punishment were blackmail allowed. The importance of this dilution in sanctions is great when one takes into account two groups of individuals who frequently have information about criminals but also have easy access to the criminal justice system: law enforcement officers and the victims of crime. If each were free to blackmail criminals, there would be a pronounced alteration from punishment by the criminal justice system to punishment through blackmail, with a substantial decrease in the magnitude of punishment.

The conclusion from this analysis of the effect of the illegality of blackmail on deterrence of crime is then ambiguous in principle, since the likelihood of punishment should fall even though the magnitude should rise. ${ }^{29}$

${ }^{28}$ Of course, many people will neither report crime nor commit blackmail, but the illegality of blackmail can only increase reporting to the state by people who already possess information about crime.

${ }^{29}$ See Jennifer G. Brown, Blackmail as Private Justice, 141 U. PA. L. REv. 1929, 1986 (1993). The conclusion, however, treats all else as given. I will argue below that when the possibility of rewarding people for reporting crimes is taken into account, the conclusion will change. The legality of blackmail should not be looked upon as needed to increase the probability of punishment, since the offer of rewards can 


\section{Commonly Made Threats in Commercial Life and Other} Legally Permissible Threats

There are a multiplicity of threats that are not illegal. I will make no attempt to characterize them, as they are so various, but will consider three for contrast with the types of illegal threats discussed above. The first is the typical threat made in commerce, to withdraw business unless price (or some other term) is favorably adjusted-for instance, a buyer's threat that he will not purchase an item unless the price is lowered from $\$ 100$ to $\$ 75$. Such threats are often made credible by the existence of alternative opportunities. If the buyer could indeed buy the item for $\$ 75$ elsewhere and the seller knows this, the buyer's threat would be credible. The fact that such threats may be made and carried out leads to changes in preparatory behavior, that is, in a buyer's search for relevant markets and a seller's efforts to lower costs enabling him to meet demands.

A second legal threat of interest is the right of a person who suffers a civil wrong to bring suit against the injuring party unless he is paid an amount in settlement. This threat is made credible by the ability of the injured party to go to court and collect a judgment. A natural question to be asked about the legality of such threats is whether they allow substantially reduced punishment of liable parties. It seems that they do not, at least in a comparative sense: settlements in the civil context should not permit as much reduction in punishment as would "settlements" of criminal cases (legal blackmail arrangements between victims of crimes and criminals). Contrast, for instance, the likely settlement in a civil case in which the defendant would be liable for $\$ 50,000$ with the criminal case in which the embezzler with only $\$ 5000$ in assets would be imprisoned for fifteen years. In the civil case, the settlement would approximate $\$ 50,000$, the social sanction, whereas in the criminal case, the settlement of $\$ 5000$ would represent far less punishment than the social sanction of lengthy imprisonment. The source of the difference is that the civil sanction is monetary, while the criminal sanction includes imprisonment.

A third example concerns a threat to take some action with one's property unless one is given a payment or something else of value in exchange. For example, a person might threaten to erect a fence around his property that his neighbor would find objection- 
able unless the neighbor agrees to constrain his bothersome dog. Such threats may or may not be credible, depending notably on whether the threatened act appears to be in the self-interest of the threatening party (whether a person is really bothered by his neighbor's dog or whether a person would find his own fence objectionable).

\section{NORMATIVE ANALYSIS OF ThREATS}

\section{A. General Effects of Threats on Social Welfare}

The influence of threats on social welfare can be divided into three categories. The first is the welfare consequences of threats for preparatory behavior. As a general matter, efforts expended by threateners putting themselves in a position to carry out threats is a social waste; such effort is not producing anything of value for final consumption. Similarly, precautions taken by potential victims avoiding threats reduce social welfare. The scaling back of activities that expose victims to the risk of threats, however, may or may not be socially undesirable, depending on the social value placed on those activities. If an activity is socially disapproved, such as a criminal activity, then any reduction in its level due to threat-making is socially desirable.

The second category is the welfare consequences of the making of threats themselves. I mention this because the making of threats, independently of whether they eventually are executed, can create fear and anxiety in victims. ${ }^{30}$ This disutility, especially if it extends over a long period, is potentially a significant detriment to social welfare. Thus, it would seem to be most relevant in a context of repeated threats, or at least where there is a long-lasting ability to carry out threats. It also needs to be noted that the fear of execution of threats is explicable in terms of our analysis. As previously mentioned, the possibility of miscalculation by the parties can lead to the blackmailer carrying out his threats. Accordingly, it

${ }^{30}$ Although it is customary in economic analysis to restrict attention to actual outcomes, such as whether a threat to expose an embarrassing fact is ultimately carried out, in the present context it seems important to take into account the effect of the risk of the actual outcome on the mental state of the threatened party. It seems that when the risk surpasses some threshold, the threatened party will worry, that is, play over in his mind what would happen if the threat were carried out, and that this type of mental activity creates substantial disutility. If so, worry is a factor that ought to weigh in the welfare calculus, along with any "actual outcome." 
is rational for a victim in a context of repeated threats to harbor a fear that at some point, a threat may be carried out.

The third category is the welfare consequences flowing from payment of demands or the carrying out of threats. If a payment is made, we often think of this as having no welfare significance in itself, as being a mere transfer of purchasing power, and I will make this assumption unless otherwise noted. But what will be of consequence to welfare is the carrying out of threats, due to imperfect information and miscalculation. The nature of the welfare effects of the execution of threats depends on the type of threat. If the threat is to do harm to a person or to property, it will lower welfare, other things being equal. If the threat is to reveal information, it may or may not be undesirable. ${ }^{31}$

The overall effect on welfare of the making of threats, therefore, is determined by the net impact of the three sources of welfare change due to threats.

\section{B. Optimal Use of the Law Against Undesirable Threats}

If it is desirable to discourage the making of threats because they lead to undesirable consequences, the law can be applied at three different stages: to the preparatory behavior of potential threateners, to the making of the threats, and to the collection of payments or the execution of threats.

When is it socially desirable for the law to intervene? The answer is that if deterrence is weak, as I will suggest will often be the case, the law should intervene at all three stages; all available opportunities to deter the unwanted behavior should be taken. ${ }^{32}$

With regard to the preparatory behavior of threateners, we can imagine that if a person is setting up eavesdropping devices for the purpose of blackmail, there is an opportunity for legal intervention. This legal strategy, however, suffers from the difficulty in differentiating innocent behavior from that which is preparatory to the making of threats. If, for instance, a person is prowling the halls of

31 See infro part II.C.

32 This argument implicitly rests on the assumption that society cannot necessarily raise deterrence adequately by increasing the magnitude of punishment. Hence, society may need to increase the number of occasions in which it punishes in order to achieve a deterrence goal. See Steven Shavell, Deterrence and the Punishment of Attempts, 19J. LEGAL STUD. 435, 436-37 (1990) (explaining why, to achieve deterrence, it may be desirable for society to punish not just acts that result in harm, but also acts that happen not to-namely, attempts). 
a motel with a camera, it will be hard to demonstrate from this alone that he was planning to take photographs for blackmail; or if a person is walking the streets searching for a robbery victim, it will be hard to demonstrate that this was his intent.

When the law is applied to the making of threats, there are also problems with deterrence. With regard to all three types of threat, there is the basic problem that the threatener selects his time and method of threat-making so as to avoid detection. Blackmail, as discussed, also involves the perversity that if the victim reports the threat, this itself may result in the revelation of information that he seeks to avoid. Further, as also discussed, blackmail and extortion threats may be hard to substantiate. Altogether, then, one supposes that the use of penalties only for the making of threats would not be sufficient to generate adequate deterrence of threats.

When the law is applied at the third stage, where payments are made or where threats are carried out, there again may be problems with detection. ${ }^{33}$ Consider first that it may not be easy to catch a person collecting a payment. He can arrange a surreptitious pickup of funds (using agents, drop-offs, and the like) or other devices (such as "buying" property at a reduced price). Further, what if he is caught taking money? Without any direct evidence about his having made a threat, it might be hard to obtain a conviction of a person who took payment, since this in itself is not illegal (a threatener might say that he merely found money in a bag). If, though, the person who took payment could be shown to have directed an effort to do so secretly, a conviction would be easier. Thus, catching a person taking payments would be likely to result in a conviction only in the latter case or where there already existed some, but not sufficient, evidence of threat-making (if proof of threat-making had been sufficient, a conviction would already have been obtained). Consider next the carrying out of threats. Again, this will be done by threateners in such a way as to avoid detection, and as was mentioned above, in the case of blackmail, is not a crime in itself.

This discussion suggests that the ability to deter threats is weak enough to warrant legal intervention at all three stages, not just at the stage of the making of threats.

${ }^{33}$ Here, I speak only about extortion and blackmail, as I assume that the second and third stages of threat-making are coincident in the case of robbery. 


\section{Application to Different Types of Threat}

\section{Robbery and Extortion}

As indicated earlier, robbery and extortion generate a substantial amount of preparatory activity on the part of potential victims and potential threateners, all of which is a social waste. Moreover, the threats generate anxiety on the part of potential victims. With robbery, the anxiety may be short-lived, if intense, although the memory of the event can create disutility. With extortion, which is likely to be repeated, the anxiety is suffered over a long period.

Also, the threats involved in robbery and extortion are to do harm to person or property, and since threats are sometimes carried out, this is another element that makes robbery and extortion socially undesirable. If the threats are not carried out, there are transfers of funds. If we regard these transfers as a wash, then there is no more to say about them. But when extortion affects businesses, as it frequently does, product prices will often rise as a consequence. This in turn will lower social welfare in a familiar way: consumers will be led to purchase alternative goods that they do not really prefer and which are not really cheaper but only appear so because of the high extortion-related price of goods sold by extorted merchants.

In sum, the effects of robbery and extortion are unambiguously to reduce social welfare, which justifies the use of legal rules against these threats.

\section{Blackmail}

Consider first blackmail where the information that might be disclosed pertains to a socially harmless activity or fact. An example is engaging in conventional sexual intercourse with one's spouse, or even taking a shower, where in either case the blackmail threat is to reveal photographs of the activity. Note that it is perfectly rational for the blackmail victim not to want such photographs revealed even though the activity in question is socially harmless. Personal modesty would lead most people not to want such photographs revealed; a very definite positive value, perhaps high for some people, would be put on preventing their revelation.

In such cases, blackmail is almost, but not entirely, analogous to robbery or extortion and thus seems socially undesirable. Specifically, the efforts to undertake blackmail and the efforts to guard against it are social wastes, and the reduction in the scale of 
potential victims' activities is a social detriment since the activities are not harmful yet benefit those who engage in them. If people take showers less frequently (for example, when they are in hotel rooms), they experience a loss in utility for no socially good reason. The making of threats also creates anxiety, which has a similar negative effect on one's welfare.

But the influence on social welfare of the actual revelation of information, should it occur, is ambiguous. By assumption, revelation of information always harms the victim. However, the effect on others of revelation of information is unclear. Consider the case of photographs of a person taking a shower being sent to the person's co-workers. It could be that those who see the photographs would not enjoy viewing them in any sense; rather, they would feel awkward, especially when in the presence of the blackmail victim. Another possibility, though, is that people might enjoy seeing photographs of a person taking a shower. For example, the blackmail victim may be an extremely attractive young woman and her male co-workers may take a prurient interest in the photographs. Thus, in theory, it is not apparent how revelation of information would affect social welfare.

Because the exposure of information when blackmail threats fail may produce a net social benefit, it is theoretically possible that blackmail is not socially undesirable even though the acts in question are socially innocuous. This case, however, seems a rather unlikely one (and it must always be kept in mind that the whole issue of exposure of information is limited in importance because it applies only when blackmail does not succeed and the blackmailer nevertheless carries out his threat). Thus, it appears that one may safely conclude that blackmail is generally socially harmful when the act threatened to be exposed is socially harmless. ${ }^{34}$

Consider next blackmail where the information pertains to a socially harmful activity other than a crime, for example, the wasteful but not illegal spending of church funds by a minister. The primary difference between this case and the previous one is that here, to the extent that blackmail reduces victims' activities, it is socially

34 This justification for the illegality of blackmail incorporates what others have said. In particular, Ginsburg and Shechtman emphasize the notion that blackmail encourages blackmailers to expend effort on gathering embarrassing information. See Ginsburg \& Shechtman, supra note 5, at 1859-65. Further, the closely related explanation for the illegality of robbery-that it induces wasteful effort on the part of both robbers and victims-is commonplace. 
valuable. If ministers are induced to use church funds more responsibly because of fear of blackmail, this is a good thing. ${ }^{35}$

That blackmail in the present case has the beneficial aspect of suppressing undesirable activities, and yet causes wasteful efforts to obtain information and to guard against blackmail, renders the social evaluation of blackmail ambiguous. To amplify, it is not possible to say whether the effort expended to undertake and avoid blackmail is more or less important than its effect in reducing undesirable activities. For example, it could be that potential victims of blackmail can almost entirely avoid detection if they make an expenditure of effort (suppose the minister can avoid detection if he goes to the trouble of making all purchases with cash instead of his credit card). If so, the primary effect of blackmail threats would be to induce expenditure of effort, not to reduce the scale of victims' activities, and blackmail would thus be socially undesirable. Conversely, if there is little potential victims can do to prevent blackmail, and its principal effect would be to reduce their undesirable activities, blackmail would be socially advantageous.

Now consider blackmail where the information that would be revealed is that a person committed a crime. Recall from previous discussion ${ }^{36}$ that blackmail should generally increase the probability that a criminal is punished in the sense that he will be blackmailed more often, but that the magnitude of punishment in the form of blackmail will frequently be lower than the specified legal sanctions. This means that the effect of blackmail on deterring crime is unclear, and thus we cannot say whether or not the blackmail of crime is socially desirable. If we allow blackmail of thieves, then more thieves would be punished because they would be forced to pay blackmail rather than go scot-free. On the other hand, some thieves who today would be reported and go to prison would instead pay modest amounts to blackmailers.

There is, however, an important factor not yet considered that suggests that blackmail need not be viewed as necessary to increase the likelihood of punishment. Suppose that society offers rewards to people for identifying criminals whenever this would be socially beneficial. Rather than inducing individuals to obtain information by allowing them to blackmail someone, like a thief, these individu-

${ }^{35}$ Additionally, if information is revealed, such disclosure is perhaps more likely to be socially beneficial here because it may allow desirable actions to be taken as a consequence, such as the church's more careful monitoring of its spending.

${ }^{36}$ See supra part I.D. 
als could be equivalently induced, were that desired, by offering them a reward equal to the amount they could obtain through blackmail-and by making blackmail illegal at the same time. What, though, is the affirmative argument for making blackmail illegal and having the state impose sanctions? One reason has already been discussed-the state can impose higher penalties, in the form of imprisonment and the stigma accompanying criminal convictions, than blackmailers. Thus state-imposed sanctions achieve a more appropriate level of deterrence. Second, presuming the judicial process has been designed to guard against errors, it is better to have this mechanism determine punishment than blackmailers. Third, in some circumstances, blackmailers would devote socially excessive efforts to finding information about criminals. ${ }^{37}$ Hence, my conclusion is that blackmail should be made illegal in the present case. ${ }^{38}$

Two further comments are worth making about blackmail and information about crime. First, the argument just given hardly implies that society does not want to take advantage of the information that people have, or can readily obtain, about criminality. On the contrary, society should seek to harness the information that people have about criminality-this is often far more efficient than having law enforcement officials try to obtain the information. The argument is that society can obtain the information through the use of rewards.

${ }^{37}$ Landes \& Posner, and recently Posner alone, have asserted that if blackmail were legal, blackmailers would generally devote socially excessive efforts to finding information. See Landes \& Posner, supra note 5, at 43; Posner, supra note 5, at 182733. However, this is only a possibility, not a general tendency. Indeed, an important example for our purposes is that when the criminal sanction includes jail, and criminals have relatively small assets, the prospect of blackmail would hardly result in excessive private efforts to find criminals-private efforts would be inadequate. In addition, private incentives to find wrongdoers may be inadequate even if sanctions are entirely monetary; this point is developed in an intellectually compelling way by A. Mitchell Polinsky. See A. Mitchell Polinsky, Private Versus Public Enforcement of Fines, 9 J. LEGAL STUD. 105, 107 (1980) (concluding that " $[$ r]egardless of relative enforcement costs, private ... enforcement leads in a wide range of circumstances to less enforcement than public enforcement, rather than more").

38 This conclusion differs from that reached by Brown, see supra note 29 , at 1943 , because I, unlike Brown, allow for the state to employ rewards. The conclusion is the same as that of Landes \& Posner, supra note 5, at 42, and Posner, supra note 5, at 1823-27, but my justification for it differs from theirs. They would find the legalization of blackmail of criminals socially undesirable because it would generally stimulate excessive efforts to find criminals, but as I have explained, see supra note 37, this is incorrect. 
Second, in the case where the parties with information are law enforcement officers, there is an additional set of disadvantages with permitting blackmail, that is, with allowing officers to collect privately arranged bounties from criminals as payment for their work. Strong incentives would be created for law enforcement officers to invent offenses and then profit from blackmail (such incentives are not strong when individual arrests have small impact on the well-being of enforcement officers). In addition, excessive risk would be imposed on enforcement officers, since an officer's pay would depend on whether he happened to make a successful arrest. Also, officers' allocation of efforts toward detecting different types of criminals would be skewed. For instance, a poor murderer would not be sought after since he could not pay much, whereas a wealthy man who got involved in a brawl would be a prime target. Similarly, the allocation of effort among different law enforcement tasks might be distorted; too much energy would be devoted to activities leading to final detection and not enough to background work. Altogether, then, the advantages of making blackmail illegal for law enforcement officers seem eminently clear.

\section{Commonly Made Threats in Commercial Life and Other Legally Permissible Threats}

The general analysis of the welfare effects of threats suggests that the threats we discussed in Part I.D ought not be discouraged or made illegal. First, it is obvious that threats to withdraw business unless price or some other term is altered are usually good things. Such threats are part of the competitive process and promote efficiency. When a seller is induced by the prospect of threats of withdrawal of business to operate at a lower cost, this is socially desirable; where a threat is actually carried out and a person takes his business elsewhere because he can secure a more favorable arrangement, this is also socially desirable. Second, with regard to threats to bring civil suits, it was suggested before that the settlement process does not seriously compromise deterrence, unlike blackmail arrangements between a victim of a crime and a criminal. Thus, a concern about deterrence is not a reason to bar civil settlements, and their legality can be justified by the savings in litigation costs and reduction of risk that they engender. Third, with respect to the other types of threats mentioned herein, many are not socially undesirable, or at least hard to delineate as suchthey are part of the normal bargaining process. A threat to fence 
off one's property unless a dog is restrained will tend to result in the dog being restrained unless the fence is cheaper to erect. It is true that threats made during bargaining can involve bluffs and result in social waste (such as when a person begins to erect a fence to demonstrate his willingness to carry forward with the threat). But such undesirable outcomes generally emanate from the inability of one of the parties to gauge the other side's position. In such cases, the courts are unlikely to have information superior to the parties and will thus be unable to intervene beneficially.

\section{Concluding Comments}

I want to conclude with several observations about the so-called paradox of blackmail and about the economic analysis of blackmail, extortion, and robbery.

Some writers have described the illegality of blackmail as paradoxical in that it makes punishable the threat to reveal information even though revealing information itself is not punishable. ${ }^{39}$ This does not seem paradoxical, however, when viewed through the lens of economics. We know that permitting blackmail will lead potential victims to curtail innocent behavior and take other steps to avoid blackmail, and also will induce potential blackmailers to invest efforts in obtaining embarrassing information. These effects are undesirable and warrant making blackmail illegal. We also know that people usually have little reason to gather embarrassing information or to reveal it if they are not profiting from blackmail threats. Thus, there is no clear reason to make the revelation of information unaccompanied by threats illegal.

Of course, a resolution of the paradox of blackmail need not be cast in economic terms, that is, in terms of the effects of blackmail, and Lindgren has criticized the economic explanation in his influential article. One of Lindgren's primary criticisms ${ }^{40}$ concerns information that is adventitiously acquired, such as when a workman going up a ladder happens to look into a room and sees

${ }^{39}$ See Lindgren, supra note 1, at 670 (noting that "[i]n blackmail, the heart of the problem is that two separate acts, each of which is a moral and legal right, can combine to make a moral and legal wrong"); Williams, supra note 1, at 162-63 (demonstrating that a demand and a threat can both be lawfully made, but taken together, they constitute blackmail).

${ }^{40}$ See Lindgren, supra note 1 , at 695 (noting that "[i]f our principal concern is to discourage people from digging up damaging information, it makes no sense to punish people for selling innocently acquired information"). 
someone in awkward circumstances. In such a case, the workman is not induced to go up the ladder to gain an opportunity for blackmail; he is going up the ladder anyway. Lindgren thus says, correctly, that the illegality of blackmail in such a case cannot be explained by a need to discourage wasteful efforts to obtain information. Nevertheless, there is still an obvious incentive-based reason for making blackmail illegal: to avoid being blackmailed by workmen or others who might by chance be present, potential victims will exercise excessive precautions or reduce their level of innocent, yet embarrassing, activities.

Although it seems to me that economic analysis supplies a sound justification for the illegality of blackmail, I do not think that it offers an explanation that jurists, lawyers, or legislators generally would find congenial. Instead, I suspect that most individuals view blackmail as deserving of punishment because it is an act that is very close to robbery, which they believe to be wicked, and because blackmail involves the calculated imposition of suffering upon its victims.

In any event, independent of any light economic analysis may shed, or fail to shed, on why the law is as we find it, economic analysis has its two usual virtues. First, it helps to describe behavior, which sometimes has complex and interesting aspects (such as the repetition of blackmail and extortion threats). Second, it aids in making recommendations. Thus, for example, the analysis suggests that although blackmail should be illegal even when the information that would be exposed pertains to crimes, we should perhaps consider making greater use of rewards for reporting crimes. 
